\title{
СРАВНИТЕЛЬНАЯ ХАРАКТЕРИСТИКА БАЗИСНЫХ ИССЛЕДОВАНИЙ ГРАНУЛОМЕТРИЧЕСКОГО СОСТАВА ОКИСИ ЦИНКА
}

\author{
${ }^{1}$ А.Ю. Атаева, ${ }^{2}$ Г.И. Свердлик, ${ }^{1}$ А.Р. Атаев
}

1 - Грозненский государственный нефтяной технический университет им. академика М.Д. Миллионщикова, г. Грозный, Россия 2 - СКГМИ (ГТУ), г. Владикавказ, Россия

В работе исследуется окись цинка методом центрифугирования. Проведения данного этапа исследований обусловлено экспериментальными испытаниями улавливания пыли с помощью разработанной установки струйного барботера запатентованной конструкции. Приводятся результаты экспериментов сравнительного анализа различных базисов одного и того же распределения.

Ключевые слова: газовые выбросы, наночастицы, оксид цинка, рентгеновский принцип детекции, базис взвешивания.

Выброс недостаточно очищенных производственных отходящих газов приводит к увеличению концентраций отдельных токсичных компонентов в воздухе. Применяемые газоочистные системы не обеспечивают улавливание мелкодисперсной пыли размером менее 40 мкм и особенно наночастиц [1].

Опасными загрязнителями окружающей среды являются предприятия, выбрасывающие частички пыли, содержащие практически все извлекаемые цветные и редкие металлы. Одними из таких металлов являются цинк, свинец, кадмий, индий и др. Окись цинка можно извлечь из пылей и шламов металлургических комбинатов и использовать в качестве сырья [2].

Исследования оксида цинка обусловлено его фотокаталитической активностью. Благодаря сочетанию 
практически важных свойств окись цинка может широко применяться в виде антикоррозионных покрытий.

Из-за своих антисептических действий оксид цинка представляет интерес в качестве компонентов различных препаратов. Используется для образования защитного барьера от воздействия раздражающих факторов. Таким образом, необходимы экспериментальные исследования для более точной оценки возможности использования наночастиц оксида цинка.

Исследования процессов пылеулавливания в СКГМИ (ГТУ) проводятся на созданной экспериментальной лабораторной установке [3], запатентованного барботажного аппарата [4]. Она представляет собой фрагмент пылегазоуловителя [5] с промышленными размерами колпаков.

Для измерения размера частиц оксида цинка использовался порошок, изучения которого проводились на установке Brookhaven XDC (далее прибор или анализатор) методом центрифугирования.

По сравнению с другими методами, рентгеновский принцип детекции, используемый в приборе, имеет преимущества: поглощение рентгеновского излучения пропорционально массе материала в исследуемой области раствора, этот метод не требует коррекции на оптические свойства материала частиц.

Перед измерением анализатор включался за 40-50 минут, для прогрева и стабилизации электронных компонентов. Для правильной процедуры измерение делается на растворе Glycer $5 \%$ с дистиллированной водой и заливается в диск. Устанавливаются параметры образца, выбирается режим, время, скорость вращения диска и измеряется верхняя базовая линия. Пластиковым шприцом с гибким шлангом отбирается образец из диска.

Оксид цинка, массой 0,2 г взвешивалась на лабораторных весах ЛВ СП.005.048 РЭ. 
Из порошка оксида цинка и раствора Glycer 5\% приготавливалась суспензия, которая предотвращает нежелательную агрегацию. Полученная суспензия диспергируется в ультразвуковой ванне в течение 3-5 минут. После диспергирования суспензия заливается в диск и при перемешивании измеряется нижняя базовая линия, поглощения гомогенной суспензией частиц. После прекращения перемешивания образца, запускается процедура измерения седиментационной кривой.

Полагается, что для гомогенной суспензии поглощение рентгеновского излучения пропорционально массовой концентрации суспензии в измеряемом объеме образца.

На рисунке 1 показано дифференциальное распределение частиц по размерам, измерения которых были проведены в разных базисах: определение среднечислового размера (N), определение среднего размера, взвешенного по поверхности $(\mathrm{S})$ и определение среднего размера по массе или по объему (V).

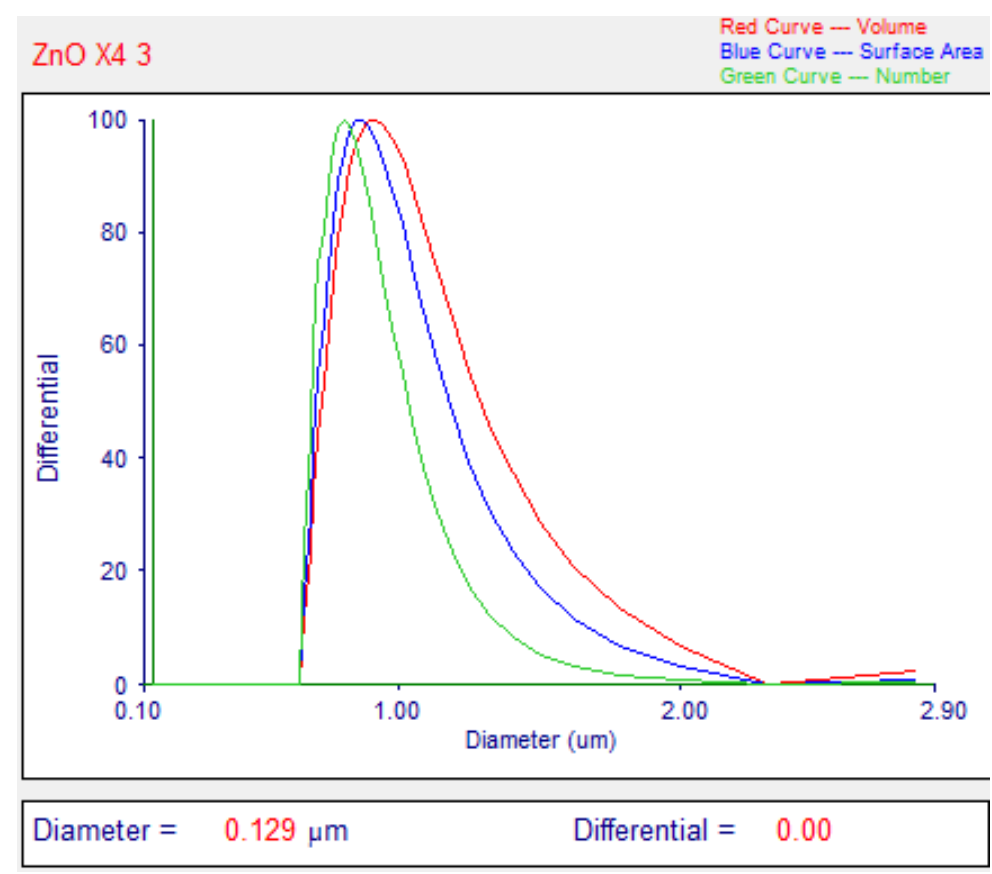

Рис. 1. Дифференциальные кривые распределения частиц по размерам 
На рисунке 2 показано интегральное распределение частиц по размерам, проведенных в разных базисах:

- Red curve - volume - красная кривая взвешивание по объему (массе) частиц;

- Blue curve - surface area - синяя кривая взвешивание по поверхности частиц (площадь поверхности кривой);

- Green curve - number - зеленая кривая взвешивание по числу частиц.

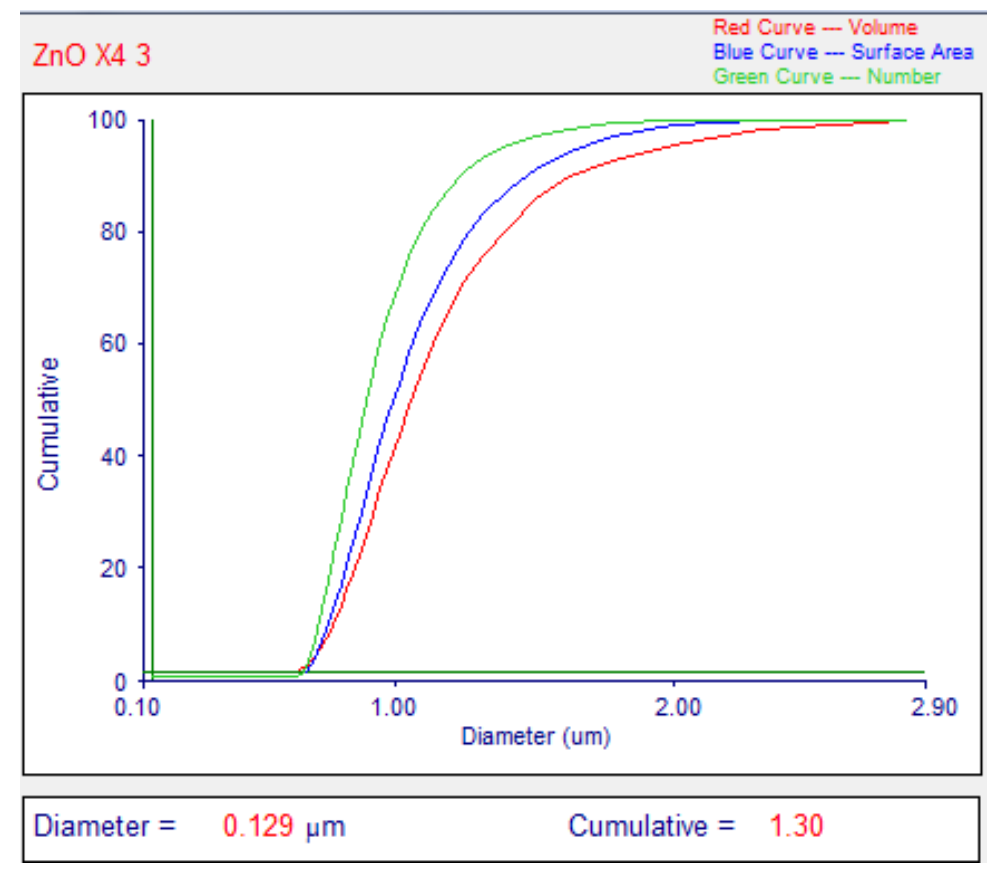

Рис. 2. Интегральные кривые распределения частиц по размерам 


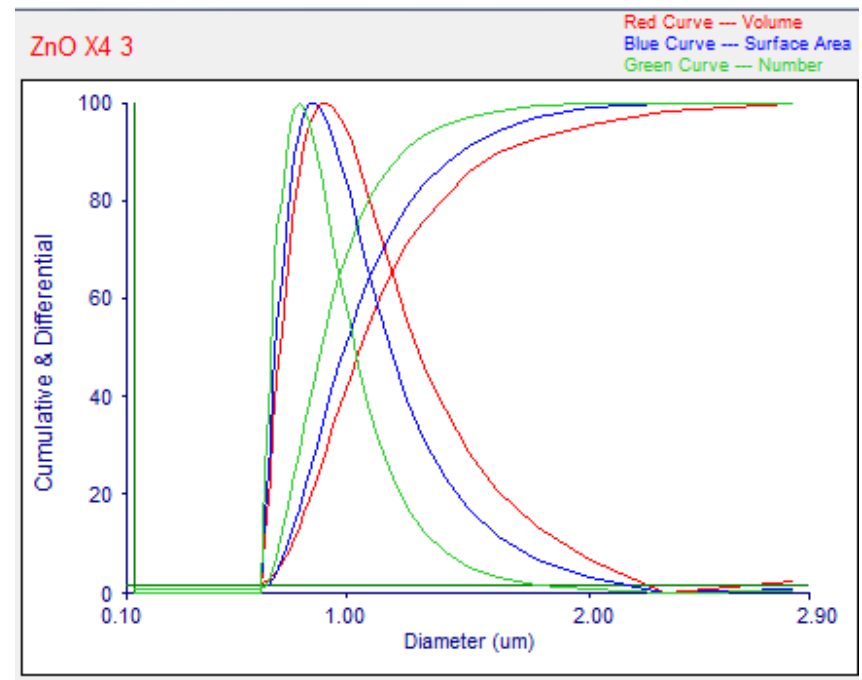

Diameter $=0.129 \mu \mathrm{m} \quad$ Cumulative $=1.30 \quad$ Differential $=0.00$

Рис. 3. Дифференциальные и интегральные кривые распределение частиц по размерам

Из рисунков 1 и 2 мы видим, что для реальных распределений кривая с численным базисом взвешивания лежит в области более мелких частиц, чем кривая с поверхностным базисом. Она в свою очередь лежит левее кривой с объемным (массовым) базисом.

Как показывают исследования с помощью высокого разрешения распределения частиц, окись цинка является высокодисперсным объектом таблица 1. Это не всегда учитывалось в теоретических оценках, обычно используются приближенные значения.

Таблица 1

\begin{tabular}{|c|c|c|c|}
\hline \multicolumn{4}{|c|}{ Analysis Results: Volume/Mass } \\
\hline d10 & $=0.783 \mu \mathrm{m}$ & Mean & $=1.155 \mu n$ \\
\hline d16 & $=0.827 \mu \mathrm{m}$ & Std.Deviation & $=0.382 \mu n$ \\
\hline$d 50$ & $=1.061 \mu \mathrm{m}$ & Mode & $=0.921 \mu n$ \\
\hline$d 84$ & $=1.469 \mu \mathrm{m}$ & FWhM & $=0.562 \mu n$ \\
\hline$d 90$ & $=1.645 \mu \mathrm{m}$ & Fw/HM/Mode & $=0.610$ \\
\hline \multicolumn{4}{|c|}{ Span=[(d90-d10]/d50 = 0.812 } \\
\hline$d 75 / d 25$ & $=1.471$ & & \\
\hline$d 84 / d 50$ & $=1.384$ & Geometric Mean & $=1.105 \mu n$ \\
\hline$d 50 / d 16$ & $=1.283$ & Geometric Std.Dev. & $=1.333 \mu n$ \\
\hline \multicolumn{4}{|c|}{ Specific Surface [Sw=1.005 sq m/g } \\
\hline
\end{tabular}


Работа выполнена с использованием оборудования Центра коллективного пользования ЦКП СКГМИ (ГТУ), где создана вышеописанная экспериментальная установка.

\section{Литература}

1. Атаева А.Ю., Свердлик Г.И., Дреев З.М. Исследование характеристик пыли и анализ методов пылеулавливания. Труды СКГМИ (ГТУ) № 23, Владикавказ, 2016, с. 142-146.

2. Безопасность жизнедеятельности: Учебник / Под ред. проф. Э.А. Арустамова. - 10-е изд., перераб. и доп. - М.: Издательско-торговая корпорация «Дашков и $\mathrm{K}^{0} », 2006 .-476 \mathrm{c}$.

3. Атаева А.Ю., Свердлик Г.И. Разработка экспериментальной установки для исследования процессов очистки пылегазовых выбросов предприятий предгорной зоны // Устойчивое развитие горных территорий, Владикавказ, 2017 - т. 9 № 1 (31), с. 92-96.

4. Свердлик Г.И., Выскребенеи А.С., Атаева А.Ю. Распределительная тарелка массообменного аппарата для мокрой очистки газа. Патент РФ № 2303479. БИ № 21, 2007.

5. Свердлик Г.И., Выскребенеи А.С., Атаева А.Ю. Разработка конструкции струйного барботера. Сборник научных трудов СКГМИ (ГТУ) № 11, Владикавказ, 2013, с. 30-32. 